\title{
Effect of total splenectomy in the lipid profile in mice ${ }^{1}$
}

\author{
Bianca Lacerda DemunerI, Gotardo Zini Pinho", João Cunha Thomaz ${ }^{\mathrm{III}}$, Nataly Pescinalli Stegmiller ${ }^{\mathrm{IV}}$, Roberta Miranda de \\ Araújo Mendesv, Marcela Souza Lima Paulovi, Danilo Nagib Salomão PauloviI
}

DOI: http://dx.doi.org/10.1590/S0102-865020150050000001

I'Graduate student, School of Medicine, Scientific Initiation Program PIBIC-FAPES, College of Health Sciences, EMESCAM, Vitoria-ES, Brazil. Interpretation of data, manuscript preparation.

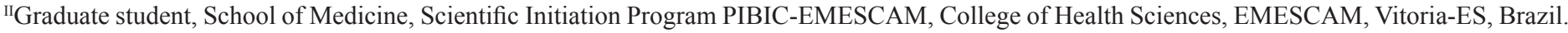
Technical procedures, acquisition of data.

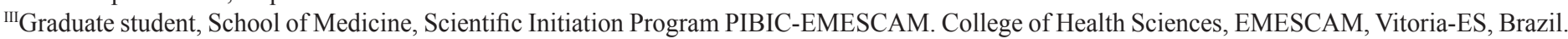
Blood collection and analysis.

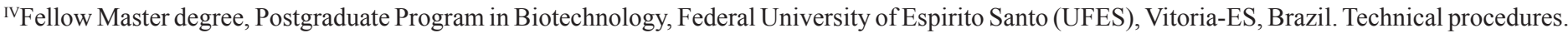
${ }^{v}$ Veterinarian, ICALP Research Center, College of Health Sciences, EMESCAM, Vitoria-ES, Brazil. Conception and design technique of blood collection.

${ }^{\mathrm{V}}$ Fellow PhD degree, Postgraduate Program in Surgical and Ophthalmological Applied Sciences, Federal University of Minas Gerais (UFMG), Belo Horizonte-MG, Brazil. Critical revision.

${ }^{V I I P h D}$, Chairman, Full Professor of Surgery, ICALP Research Center, College of Health Sciences, EMESCAM, Vitoria-ES, Brazil. Intellectual and scientific content of the study, manuscript writing, critical revision.

\begin{abstract}
PURPOSE: To analyze total splenectomy effect on the lipid profile - total cholesterol, low-density lipoprotein cholesterol (LDL), highdensity lipoprotein cholesterol (HDL), very-low-density lipoprotein cholesterol (VLDL) and triglycerides levels, in Balb/c mice.

METHODS: Thirty Balb/c male mice, one (1) month old and average weight $26.2 \mathrm{~g} \pm 4.0$ were used in the experiment. They were distributed into three groups of 10 animals each: a control group (non-operated), a simulation group (spleen manipulation) and the splenectomy group. The animals were subjected to blood sampling to measure plasma lipid levels, at three different times: before surgery, days 30 and 75 of the experiment.

RESULTS: Increased total cholesterol and LDL were observed in the control group from the start to end of the experiment. The simulation group showed increased rates of VLDL and triglycerides at the 30th and 75th days. Splenectomized animals showed no significant change.
\end{abstract}

CONCLUSION: Total splenectomy did not induce increased plasma lipids levels of in Balb/c mice.

Key words: Spleen. Splenectomy. Lipid Metabolism. Mice. 


\section{Introduction}

Spleen is responsible for numerous functions in the body such as blood clearance through hemocaterese and bacteria removal, the production of antibodies and lymphocytes, the regulation of the number of leukocytes and platelets as well as also participates in metabolic control ${ }^{1}$ and as a lipid reservoir ${ }^{2}$.

The spleen influence over the lipid metabolism has been reported in studies with human beings $\mathrm{s}^{3,4}$ and experimental animals ${ }^{1,5-9}$

There is increase in plasma cholesterol levels and LDLcholesterol after splenectomy ${ }^{3}$ in humans with myeloproliferative disorders and splenomegaly. Such data suggest the important role of spleen in cholesterol metabolism, since the organ may be an important site of LDL-cholesterol catabolism ${ }^{3}$.

King $^{5}$, observed increased cholesterol in dogs after spleen removal. Ham and Furneaux ${ }^{10}$, found no changes in lipoprotein lipase and plasma lipids in dogs two weeks after splenectomy.

Asai et al. ${ }^{6}$, studied rabbits fed with high cholesterol levels products. They observed significant increase in cholesterol, triglycerides and phospholipids as well as reduction in HDL levels in the splenectomized group if compared to simulation group. Petroianu et al. ${ }^{1}$ and Fatouros et al. ${ }^{7}$, showed increased triglycerides and low HDL in splenectomized rats fed with normal diet and with diet rich in cholesterol. Simões et al. ${ }^{11}$, suggested that total splenectomy alters lipids metabolism in rats fed with standard chow. A diet based on pork fat used as lipids source changed the animals' lipid profile ${ }^{12}$.

The authors showed ${ }^{13}$, that rats submitted to splenic surgery and fed with a nutritionally balanced diet kept plasma lipid levels and hyperlipidemia occurred with the use of cholesterol-reducing chow and cholesterol-enriched diet in rats after splenectomy.

Study by Rezende et al. ${ }^{14}$ showed that splenectomy in BALB/c mice did not increase plasma lipid fractions. These authors suggested that spleen does not participate in plasma lipids levels regulation in the herein studied mice strain. Their work, however, did not assess the extent of cholesterol levels before splenectomy, it just compared results from the control and the splenectomized groups in the postoperative period ${ }^{14}$.

Although there are strong evidences of the spleen participation in lipid metabolism, the issue is still controversial. In face of such doubt, we performed the current study aiming at verifying the effect of total splenectomy in plasma lipids of $\mathrm{BALB} / \mathrm{c}$ mice.

\section{Methods}

The study was approved by the Ethics Committee on Animal Use (Protocol No. 005/2008 - CEUA) of the College of Health Sciences (EMESCAM).

Thirty BALB/c male mice, one month old and weighing $26.2 \mathrm{~g} \pm 4.0$ were used in the experiment. They were divided into three groups of 10 animals each: a control group (non-operated), a simulation group (spleen manipulation) and the splenectomy group. The distribution was carried out by specialized technician who didn't know the group each animal belonged to. The animals were kept in proper and identified cages under adequate temperature, ventilation and lighting conditions to the studied species $^{15}$. The mice were fed with normal diet (CR-1 Nuvilab autoclavable - Nuvital ${ }^{\circledR}$ ) and with water ad libitum.

The animals were weighed (electronic scale Filizola - sensitivity $1 \mathrm{~g}$ ), and identified with markings on the tail. They underwent blood sampling after six hours, and approximately $10 \%$ of their blood volume was removed. By considering that each animal has an average of $80 \mathrm{ml}$ of blood per body kilogram and that its weight of 20 to 30 grams on average, approximately 0.16 to $0.24 \mathrm{ml}$ of blood was removed by a tail vein. The tailbleeding technique was done after the animal's tail was cleaned with $70 \%$ alcohol. The animal was placed into a wide-mouth funnel and immobilized on a support. The mouse's tail was tilted to vertical position and heated in hot water for 30 to 60 seconds. Next, a cross-section of the tail was done to removal a $5 \mathrm{~mm}$ distal. A collection tube was placed in the position and the blood was collected in order to get the aforementioned amount. Finally, each mouse was taken back to the cage and kept under observation.

We used the semi-automated enzymatic colorimetric laboratory method for the quantification of plasma lipids (total cholesterol, HDL and triglycerides) and concentrations of LDL and VLDL fractions of cholesterol were calculated by using the Friedewald formula (LDL-C $=\mathrm{TC}+\mathrm{HDLc}+\mathrm{TG} / 5$ ). The lipids dosage was done in the Siemens Dimension RxLMax equipment.

Fifteen days after blood collection, animals from groups 2 and 3 were anesthetized with xylazine, at a dose of $10 \mathrm{mg} /$ $\mathrm{kg}$, associated with intraperitoneally administered ketamine hydrochloride at $100 \mathrm{mg} / \mathrm{kg}$. The trichotomy and antisepsis of the abdominal and thoracic walls with topic PVPI, the definition of the local of the laparotomy and of the median longitudinal incision in the skin and subcutaneous tissue and the opening in the linea alba and peritoneum were done. Group 2 was submitted to spleen manipulation. Group 3, underwent total splenectomy to mobilize the spleen in the abdominal cavity. The vessels near to the spleen 
underwent ligatures and section, then the organ was removed. The abdominal wall was sutured with nylon 6.0 in two planes. After recovering from anesthesia, the animals were fed with standard diet, water and pain reliever. The new blood collection for plasma lipids dosage was done in all the animals on the 30th day after the start of the experiment. It corresponds to the 15 th postoperative day in animals from groups 2 and 3. On the 75th day of the experiment, which corresponds to the 60th postoperative day, the collections were performed in three groups of animals. The sequence of events in the experiment is shown in Figure 1.

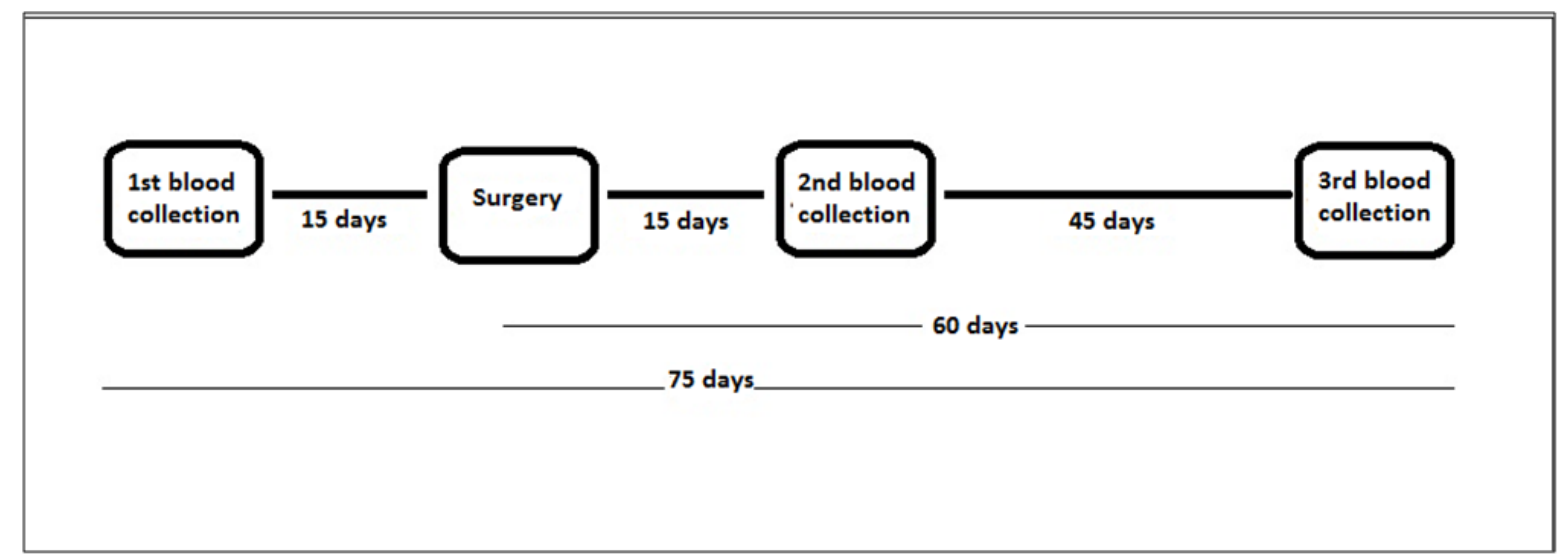

FIGURE 1 - Chronological sequence of procedures performed in three groups (control, simulation, and splenectomy) of Balb/c mice analyzed for lipid profile.

The descriptive statistics was used to calculate arithmetic mean and standard deviation of mice's weight and plasma lipid levels; the Student t-test was used in related samples to compare weight and the amounts of preoperative and postoperative cholesterol total and cholesterol fractions (HDL, LDL, VLDL and triglycerides) of animals in the same group. The " $p$ " values were considered significant when they were lower than $0.05(\mathrm{p}<0.05)$.

\section{RESULTS}

There was no significant weight change in animals since the beginning of the experiment till its 30th day in the three groups, as shown in Table 1. However, the control group showed a significant increase in weight if comparing the initial weight and the weight in the 75th day of the experiment and if comparing that of the 30th day with the weight in the 75th day of the experiment. In simulation groups and in the total splenectomy group, the changes were not significant.

TABLE 1 - The Weight (grams) of the mice in the control, simulation and total splenectomy groups, immediately before each blood collection.

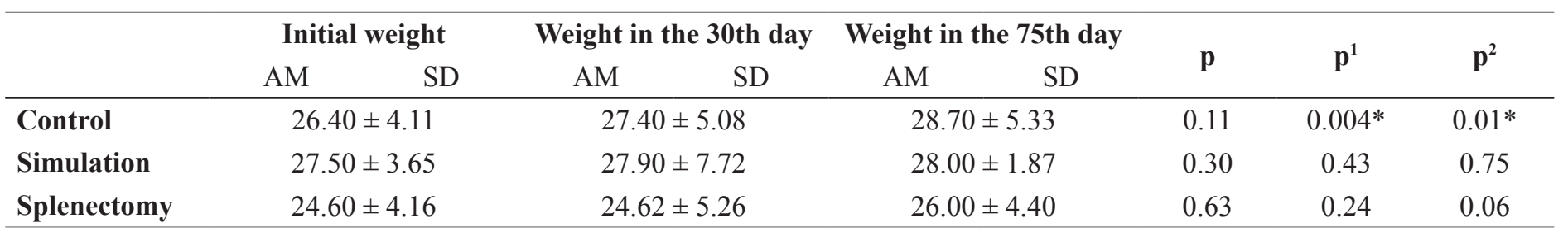

AM-Arithmetic Mean. SD-Standard Deviation. Student t-test for related samples. $\mathrm{p}<0.05$ significant* . p-comparison between the initial weight and the weight of animals in the 30th day in the same group. $\mathbf{p}_{1}$-comparison between the initial weight and the weight of animals in the 75 th day in the same group. $\mathbf{p}_{2}$-comparison between the weight in $30^{\text {th }}$ day and in $75^{\text {th }}$ day in the same group.

Two deaths were recorded in the total splenectomy group and one in the simulation group. The cause of death was not found after necropsy.

The total splenectomy surgical technique was feasible in all cases and it lasted for approximately 40 minutes. Surgery time started to be counted from incision and the ending point was the suture procedure applied to the skin. No hemorrhages, suture dehiscence or infections on the walls were observed within the operated groups.

It was not possible to perform the plasma lipids measurement in three of the blood samples from the simulation group and in a 
control group sample because of significant hemolysis in them.

Results on total cholesterol, HDL, LDL, VLDL and triglycerides in the operated and non-operated mice are shown in Tables 2 to 6.
We observe significant increase of total cholesterol in the control group in the beginning of the experiment if compared with the 75th day of experiment. The other changes in cholesterol values were not significant (Table 2).

TABLE 2 - Values of total cholesterol of the mice in the control, simulation and total splenectomy groups.

\begin{tabular}{|c|c|c|c|c|c|c|c|c|c|}
\hline & \multicolumn{2}{|c|}{ Initial collection } & \multicolumn{2}{|c|}{ Collection at the 30th day } & \multicolumn{2}{|c|}{ Collection at the 75th day } & \multirow{2}{*}{$\mathbf{p}$} & \multirow[b]{2}{*}{$p_{1}$} & \multirow{2}{*}{$\mathbf{p}_{2}$} \\
\hline & $\mathrm{AM}$ & SD & $\mathrm{AM}$ & SD & $\mathrm{AM}$ & SD & & & \\
\hline Control & \multicolumn{2}{|c|}{$86.50 \pm 17.95$} & \multicolumn{2}{|c|}{$95.62 \pm 27.37$} & \multicolumn{2}{|c|}{$106.10 \pm 15.70$} & 0.61 & $0.003 *$ & 0.52 \\
\hline Splenectomy & \multicolumn{2}{|c|}{$94.60 \pm 16.94$} & \multicolumn{2}{|c|}{$86.37 \pm 15.76$} & & & 0.38 & 0.97 & 0.38 \\
\hline
\end{tabular}

AM-Arithmetic Mean. SD-Standard Deviation. Student t-test for related samples. $\mathrm{p}<0.05$ significant*. p-comparison between the initial collection and the blood collection in the 30th day in the same group. $\mathrm{p}_{1}$-comparison between the initial collection and the blood collection in the 75th day in the same group. $\mathrm{p}_{2}$-comparison between the blood collection in $30^{\text {th }}$ day and in $75^{\text {th }}$ day in the same group.

Table 3 shows the non-significant HDL changes in the three groups throughout the experiment.

Table 4 shows LDL increase in the control group after 75 days of the experiment when it is compared to the initial value. In the simulation group, there was a decrease in the amount of LDL when the value from the 30th day and the 75th day of the study were compared.

TABLE 3 - Values of HDL-cholesterol in the mice in the control, simulation and total splenectomy groups.

\begin{tabular}{|c|c|c|c|c|c|c|}
\hline & Initial collection & Collection at the 30th day & Collection at the 75th day & & & \\
\hline & $\mathrm{AM}$ & $\mathrm{AM}$ & $\mathrm{AM}$ & $\mathbf{p}$ & $\mathbf{P}_{1}$ & $\mathbf{p}_{2}$ \\
\hline Control & $54.10 \pm 16.86$ & $60.62 \pm 14.25$ & $60.33 \pm 13.75$ & 0.85 & 0.40 & 0.93 \\
\hline Simulation & $55.00 \pm 15.82$ & $50.14 \pm 9.51$ & $56.00 \pm 5.01$ & 0.67 & 0.86 & 0.24 \\
\hline $\begin{array}{l}\text { Total } \\
\text { splenectomy }\end{array}$ & $59.10 \pm 9.76$ & $50.75 \pm 13.33$ & $57.16 \pm 13.52$ & 0.23 & 0.46 & 0.43 \\
\hline
\end{tabular}

AM-Arithmetic mean. SD-Standard deviation. Student t-test for related samples. $p<0.05$ significant*. p-comparison between the initial collection and the blood collection in the 30th day in the same group. $\mathbf{p}_{1}$-comparison between the initial collection and the blood collection in the 75 th day in the same group. $\mathbf{p}_{2}$-comparison between the blood collection in $30^{\text {th }}$ day and in $75^{\text {th }}$ day in the same group.

TABLE 4 - Values of LDL-cholesterol in the mice in the control, simulation and total splenectomy groups.

\begin{tabular}{|c|c|c|c|c|c|c|c|c|c|}
\hline & \multicolumn{2}{|c|}{ Initial collection } & \multicolumn{2}{|c|}{ Collection at the 30 th day } & \multicolumn{2}{|c|}{ Collection at the 75 th day } & \multirow[b]{2}{*}{ p } & \multirow[b]{2}{*}{$\mathbf{p}_{1}$} & \multirow[b]{2}{*}{$\mathbf{p}_{2}$} \\
\hline & $\mathrm{AM}$ & SD & $\mathrm{AM}$ & SD & $\mathrm{AM}$ & SD & & & \\
\hline Control & \multicolumn{2}{|c|}{$20.00 \pm 13.11$} & \multicolumn{2}{|c|}{$17.97 \pm 10.56$} & \multicolumn{2}{|c|}{$29.80 \pm 10.77$} & 0.94 & $0.001^{*}$ & 0.10 \\
\hline Splenectomy & \multicolumn{2}{|c|}{$21.00 \pm 7.41$} & \multicolumn{2}{|c|}{$22.25 \pm 9.67$} & & & 0.64 & 0.27 & 0.61 \\
\hline
\end{tabular}

AM-Arithmetic Mean. SD-Standard Deviation. Student t-test for related samples. $\mathrm{p}<0.05$ significant*. $\mathbf{p}$-comparison between the initial collection and the blood collection in the 30th day in the same group. $\mathbf{p}_{1}$-comparison between the initial collection and the blood collection in the 75 th day in the same group. $\mathbf{p}_{2}$-comparison between the blood collection in $30^{\text {th }}$ day and in $75^{\text {th }}$ day in the same group.

Table 5 shows that VLDL increased in the simulation group in the 30th and 75 th days of the experiment if compared to the initial value.
Table 6 shows that triglycerides increased in the 30th and 75th days of the experiment in animals subjected to splenic manipulation when their values were compared with the initial value. 
TABLE 5 - Values of VLDL-cholesterol in the mice in the control, simulation and total splenectomy groups.

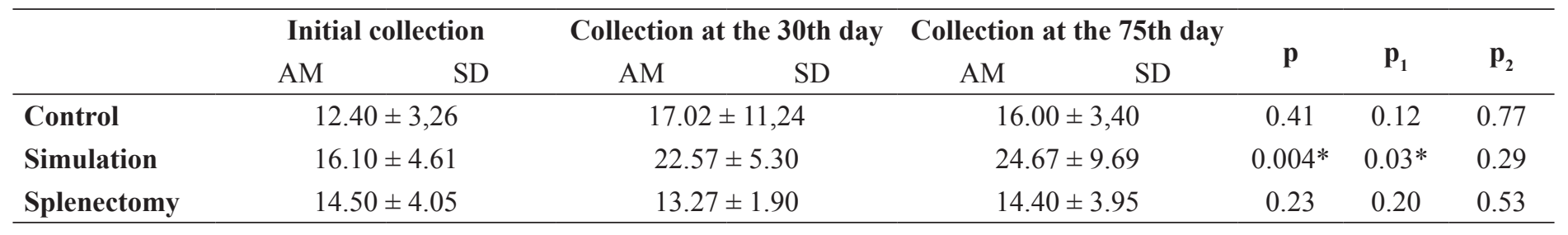

AM-Arithmetic Mean. SD-Standard Deviation. Student t-test for related samples. $\mathrm{p}<0.05$ significant*. p-comparison between the initial collection and the blood collection in the 30th day in the same group. $\mathrm{p}_{1}$-comparison between the initial collection and the blood collection in the 75 th day in the same group. $\mathrm{p}_{2}$-comparison between the blood collection in $30^{\text {th }}$ day and in $75^{\text {th }}$ day in the same group.

TABLE 6 - Values of tryglicerides in the mice in the control, simulation and total splenectomy groups.

\begin{tabular}{|c|c|c|c|c|c|c|c|c|c|}
\hline & \multicolumn{2}{|c|}{ Initial collection } & \multicolumn{2}{|c|}{ Collection at the 30th day } & \multicolumn{2}{|c|}{ Collection at the 75th day } & \multirow{2}{*}{$\mathbf{p}$} & \multirow[b]{2}{*}{$\mathbf{p}_{1}$} & \multirow[b]{2}{*}{$\mathbf{p}_{2}$} \\
\hline & $\mathrm{AM}$ & SD & $\mathrm{AM}$ & SD & $\mathrm{AM}$ & SD & & & \\
\hline Control & \multicolumn{2}{|c|}{$62.00 \pm 16.32$} & \multicolumn{2}{|c|}{$85.12 \pm 56.22$} & \multicolumn{2}{|c|}{$79.88 \pm 17.13$} & 0.41 & 0.13 & 0.76 \\
\hline Simulation & \multicolumn{2}{|c|}{$80.50 \pm 23.08$} & \multicolumn{2}{|c|}{$112.87 \pm 26.52$} & \multicolumn{2}{|c|}{$123.37+48.47$} & $0.04 *$ & $0.03 *$ & 0.29 \\
\hline $\begin{array}{l}\text { Total } \\
\text { splenectomy }\end{array}$ & \multicolumn{2}{|c|}{$72.50 \pm 20.29$} & \multicolumn{2}{|c|}{$66.25 \pm 9.46$} & \multicolumn{2}{|c|}{$72.00 \pm 19.79$} & 0.22 & 0.20 & 0.53 \\
\hline
\end{tabular}

AM-Arithmetic Mean. SD-Standard Deviation. Student t-test for related samples. $\mathrm{p}<0.05$ significant*. p-comparison between the initial collection and the blood collection in the 30th day in the same group. $\mathbf{p}_{1}$-comparison between the initial collection and the blood collection in the 75th day in the same group. $\mathbf{p}_{2}$-comparison between the blood collection in $30^{\text {th }}$ day and in $75^{\text {th }}$ day in the same group.

\section{Discussion}

By comparing the weights of animals in the 30th day and those in the 75 th day of the experiment and the weights from the beginning of the experiment to the weights at the end of it, we observed that animals in the control group showed significant weight gain. Such result may be associated with the fact that these animals were not subjected to surgical stress and it may have favored the regular feeding throughout the experiment time. The animals that underwent surgical procedures showed no significant weight changes.

The survival rate was of $90 \%$ and it included two deaths in the postoperative total splenectomy period and one in the simulation group, both death causes not found in necropsy.

The handling of the animals during the experiment was conducted without difficulties. The total splenectomy surgical technique and the spleen manipulation were feasible in all cases. Postoperative complications weren't observed. The blood sampling technique was effective and the sample volume was sufficient to the required dosages of lipid fractions. Hemolysis occurred in two samples and it may be justified by possible failures during blood collection: was it caused by the contact of the sample with the water used to heat the mouse's tail and/or was lysis caused by excessive manipulation of the animal's tail. The results that did not allow the calculation of LDL raised two hypotheses: error in laboratory determinations and the unsuitability of the Friedewald formula for the experimental test model.

When analyzing lipid levels in the three groups of animals, we observed that the mice in the control and in the simulation groups showed significant lipid changes. There was increase in total and LDL cholesterol in the control group and of triglycerides, LDL and VLDL in the simulation group. These findings may be related to greater weight gain in the control group. However, so far, there are no explanations for the aforementioned changes within the simulation group. Importantly, as in humans, other factors may be associated with increased dyslipidemia risks, among them there are genetic predisposition, poor diet, obesity and sedentary lifestyle ${ }^{16}$.

The group which underwent total splenectomy showed no significant changes in lipid fractions at any time of the experiment. These results are consistent with those reported by Rezende et al. ${ }^{14}$, who suggested that the spleen does not seem to participate in the regulation of plasma lipid levels in BALB/c mice. A recent study also showed that total cholesterol, LDL, HDL and triglycerides levels after splenectomy did not show an abnormal lipid profile on children ${ }^{17}$. However, they differ from results found in splenectomized dogs, described by Paulo and Silva ${ }^{8}$. It was the first work published in Brazil on this subject. The authors demonstrated significant increase in total cholesterol, HDL and LDL, whereas triglycerides levels and the VLDL fraction remained unchanged $^{8}$. Crary et al. ${ }^{18}$ reported reduced total cholesterol and LDL levels in patients with hereditary spherocytosis and intact 
spleen. They found higher cholesterol levels in splenectomized patients, although the high cholesterol levels were normal limits.

Spleen's participation in lipid metabolism is still controversial. Studies with different experimental models showed significant changes in the lipid profile of the splenectomized animals $1,6,7,9,19-22$. However, when part of the spleen is preserved, its viability is maintained ${ }^{23-25}$ and changes in lipid profile are not observed $^{26}$. Clinical and experimental studies seek to determine what the actual functions of the spleen in lipid metabolism are. It is necessary to perform further research in experimental models closer to the metabolic profile of humans due to the strong controversies and high morbidity and mortality rates caused by complications from the atherosclerotic disease.

\section{Conclusion}

Total splenectomy in BALB/c mice does not lead to significant increase in total cholesterol, HDL, LDL, VLDL and triglycerides.

\section{References}

1. Petroianu A, Veloso DF, Costa GR, Alberti LR. Effects of splenic surgeries on lipidogram of rats. Rev Assoc Med Bras. 2006 JanFeb;52(1):56-9. PMID: 16622541.

2. Gonçalves TB, Yamaki VN, Feijó DH, Souza LE, Silveira E, Brito MV, Petroianu A. Effects of splenic allograft in lipid profile of nonsplenectomized rats: the immune and metabolic role of the "Double spleen”. Rev Col Bras Cir. 2014 Mar-Abr;41(2):122-7. PMID: 24918726 .

3. Robinette CD, Fraumeni JF Jr. Splenectomy and subsequent mortality in veterans of the 1939-45 war. Lancet. 1977 Jul;2(8029):127-9. PMID: 69206

4. Aviram M, Brook JG, Tatarsky I, Levy Y, Carter A. Increased lowdensity lipoprotein levels after splenectomy: a role for the spleen in cholesterol metabolism in myeloproliferative disorders. Am J Med Sci. 1986 Jan;291(1):25-8 PMID: 3942157.

5. King JH. Studies in the pathology of the spleen. Arch Intern Med. 1914;14:145-67. doi: 10.1001/archinte.1914.00070140002001.

6. Asai K, Kuzuya M, Naito M, Funaki C, Kuzuya F. Effects of splenectomy on serum lipids and experimental atherosclerosis. Angiology. 1988 Jun;39(6):497-504. PMID: 3377269.

7. Fatouros M, Bourantas $\mathrm{K}$, Bairaktari E, Elisaf M, Tsolas $\mathrm{O}$, Cassioumis D. Role of the spleen in lipid metabolism. Br J Surg.1995 Dec;82(12):1675-7. PMID: 8548239.

8. Paulo DNS, Silva AL. Lipídios plasmáticos após esplenectomia total e parcial em cães. Rev Col Bras Cir. 2001 Jul-Ago;28(4):264-70. doi: 10.1590/S0100-69912001000400006.

9. Paulo ICAL, Paulo DNS, Silva AL, Foletto RM, Colnago GL, Vargas PM. Níveis de lípides plasmáticos em ratos submetidos à esplenectomia total, ligadura simultânea dos vasos esplênicos e a esplenectomia subtotal com preservação do polo inferior. Rev Col Bras Cir. 2005;32(5):229-36. doi: 10.1590/S010069912005000500003.

10. Ham JM, Furneaux RW. The effect of splenectomy on blood platelets and lipoprotein lipase activity in the dog. Br J Surg. 1969;56(7):527-
30. PMID: 5794971.

11. Simões FC, Marques RG, Diestel CF, Caetano CE, Dinis AP, Horst NL, Nogueira Neto JF, Portela MC. Lipidic profile among rats submitted to total splenectomy isolated or combined with splenic autotransplant. Acta Cir Bras. 2007 Mar-Apr;22(1):46-51. PMID: 17505655.

12. Dinis AP, Marques RG, Simões FC, Diestel CF, Caetano CE, Secchin DJ, Neto JF, Portela MC. Plasma lipid levels of rats fed a diet containing pork fat as a source of lipids after splenic surgery. Lipids. 2009 Jun;44(6):537-43. PMID: 19415360.

13. Paulo DNS, Paulo ICAL, Morais AA, Kalil M, Guerra AJ, Colnago GL, Faintuch J. Is splenectomy a dyslipidemic intervention? Experimental response of serum lipids to different diets and operations. Microsurgery. 2009;29(2):154-60. PMID: 18942648.

14. Rezende AB, Nunes SI, Farias RE, Vieira FR, Petroianu A, Teixeira HC. Influência do baço, da asplenia e do implante esplênico autógeno no metabolismo lipídico de camundongos. Rev Col Bras Cir. 2007;34(3):177-82. doi: 10.1590/S0100-69912007000300008.

15. Chorilli M, Michelin DC, Salgado HRN. Animais de laboratório: o camundongo. Rev Ciênc Farmacêuticas Básica Aplicada. 2007;28(1):11-23

16. Sociedade Brasileira de Cardiologia, Departamento de Aterosclerose da Sociedade Brasileira de Cardiologia. IV Diretriz brasileira sobre dislipidemias e prevenção da aterosclerose. Arq Bras Cardiol. 2007;88(Supl I).

17. Das A, Bansal D, Ahluwalia J, Das R, Rohit MK, Attri SV, Trehan A, Marwaha RK. Risk factors for thromboembolism and pulmonary artery hypertension following splenectomy in children with hereditary spherocytosis. Pediatr Blood Cancer. 2014 Jan;61(1):2933. PMID: 24038836.

18. Crary SE, Troendle S, Ahmad N, Buchanan GR. Traditional laboratory measures of cardiovascular risk in hereditary spherocytosis. Pediatr Blood Cancer. 2010 Oct;55(4):684-9. PMID: 20589636.

19. Shalev H, Kapelushnik J, Moser A, Knobler H, Tamary H. Hypocholesterolemia in chronic anemias with increased erythropoietic activity. Am J Hematol. 2007 Mar;82(3):199-202. PMID: 17039515.

20. Dawber TR. The Framingham study. The epidemiology of atherosclerotic disease. Cambridge: Harvard University Press; 1980.

21. van der Bom JG, Heckbert SR, Lumley T, Holmes CE, Cushman M, Folsom AR, Rosendaal FR, Psaty BM. Platelet count and the risk for thrombosis and death in the elderly. J Thromb Haemost. 2009 Mar;7(3):399-405. PMID: 19143922.

22. Khan PN, Nair RJ, Olivares J, Tingle LE, Li Z. Postsplenectomy reactive thrombocytosis. Proc (Bayl Univ Med Cent). 2009 Jan;22(1):9-12. PMID: 19169391.

23. Silva JJ, Silva AL, Paulo DNS. Subtotal laparoscopic splenectomy in rats with preservation of the inferior pole. Acta Cir Bras. 2011 Feb;26(1):44-50. PMID: 21271203.

24. Paulo MSL, Paulo ICAL, Nunes TA, Silva AL da, Cintra LC, Paulo DNS. Effect of hyperbaric oxygen therapy in rats with subtotal splenectomy preserving the inferior pole. Acta Cir Bras. 2011 Jun;26(3):156-8. PMID: 21537516.

25. Paulo MSL, Santos FTB, Rocha PG, Silva MB, Cintra LC, Motta LL, Errera FIV, Paulo DNS, Nunes TA. Immunoexpression of proliferating cell nuclear antigen (PCNA) in spleen of splenectomized rats with preservation of inferior pole, submitted to hyperbaric oxygenation. Acta Cir Bras. 2013 Oct;28(10):691-5. doi: 1590/S0102-86502013001000001.

26. aulo DNS, Paulo ICAL, Kalil M, Vargas PM, Silva AL, Baptista JF, Guerra AJ. Subtotal splenectomy preserving the lower pole in rats: technical, morphological and functional aspects. Acta Cir Bras. 2006 Sep-Oct;21(5):321-7. PMID: 16981036. 
Demuner BL et al.

\section{Acknowledgements}

To Luiz Antônio de Oliveira, Magno Pinheiro Gomes and Marcos Vinícius Gumiero for their technical support during the development of the current study at Laboratory of Animal Experimentation of EMESCAM.

\section{Correspondence:}

Danilo Nagib Salomão Paulo

Rua Santa Rita de Cássia, 777

29042-753 Vitória - ES Brasil

Tel.: (55 27)3222-1545/99854-8187

danilo.vix@terra.com.br

Received: Jan 16, 2015

Review: Mar 19, 2015

Accepted: Apr 18, 2015

Conflict of interest: none

Financial sources: Foundation for Research Support of the State of Espirito Santo (FAPES) and Institute for Sustained Development and Practical Actions in Health.

${ }^{1}$ Research performed at Laboratory of Animal Experimentation, ICALP Research Center, College of Health Sciences (EMESCAM), Vitoria-ES, Brazil. 